\title{
Assessment of HER-2 status in invasive breast cancer in Brazil
}

\author{
Victor Eduardo Arrua Arias ${ }^{1}$, Helenice Gobbi² ${ }^{2}$, Sérgio Ossamu loshiı ${ }^{3}$, Cristovam Scapulatempo ${ }^{4}$, Alexandre Rolim da Paz ${ }^{5}$, \\ Vinicius Duval da Silva ${ }^{6}$, Diego Uchôa ${ }^{7}$, Claudio Zettler ${ }^{8}$, Fernando Augusto Soares ${ }^{9 *}$ \\ ${ }^{1}$ Reference Center for Women's Health, Hospital Pérola Byington, São Paulo, SP, Brazil \\ 2Department of Pathologic Anatomy, Faculdade de Medicina da Universidade Federal de Minas Gerais, Belo Horizonte, MG, Brazil \\ 3Pathology Division, Hospital Erasto Gaertner and Pontifícia Universidade Católica do Paraná, Curitiba, PR, Brazil \\ 4Department of Pathology and Center for Research in Molecular Oncology, Hospital de Câncer de Barretos, Barretos, SP, Brazil \\ ${ }^{5}$ Hospital Napoleão Laureano, Universidade Federal da Paraiba, João Pessoa, PB, Brazil \\ ${ }^{6}$ Pontifícia Universidade Católica do Rio Grande do Sul, Porto Alegre, RS, Brazil \\ ${ }^{7}$ Hospital de Clínicas de Porto Alegre, Porto Alegre, RS, Brazil \\ 8Pathology Service, Irmandade da Santa Casa de Porto Alegre, Porto Alegre, RS, Brazil \\ ${ }^{9}$ Department of Pathologic Anatomy, A.C. Camargo Cancer Center, São Paulo, SP, Brazil
}

Study conducted at the Department of Pathologic Anatomy, A.C. Camargo Cancer Center, São Paulo, SP, Brazil

Article received: $12 / 15 / 2016$ Accepted for publication: 2/5/2017

*Correspondence: Departamento de Anatomia Patológica, A.C. Camargo Cancer Center Address: R. Prof. Antônio Prudente, 211 São Paulo, SP - Brazil

Postal code: 01509-010 fasoares@icloud.com

http://dx.doi.org/10.1590/1806-9282.63.07.566

\section{SUMmARY}

Objective: To characterize the frequency of HER-2-positive breast cancer in Brazil. Method: In this prospective observational study, we first ascertained the HER-2 status of invasive breast cancer specimens by automated immunohistochemistry (IHC). For specimens classified as 2+ by IHC, we performed in situ hybridization (ISH).

Results: From February, 2011 to December, 2012, 1,495 breast specimens were registered, and 1,310 samples collected at 24 centers were analyzed. Median patient age was 54 years, and the majority of samples were obtained from segmental (46.9\%) or radical mastectomy (34.4\%). The predominant histological type was invasive breast carcinoma of no special type (85\%), 64.3\% had tubule formation (grade 3), and estrogen/progesterone receptors (ER/PR) were positive in $77.4 / 67.8 \%$ of the specimens analyzed, respectively. Using IHC, we found a negative HER-2 status ( 0 or $1+$ ) in $72.2 \%$ of specimens, and $3+$ in $18.5 \%$; the $9.3 \%$ scored as $2+$ were further analyzed by ISH, of which $15.7 \%$ were positive (thus, $20.0 \%$ of samples were HER-2-positive by either method). We found no association between HER-2 scores and menopausal status or histological type. Tumors classified as $3+$ came from younger patients, and had higher histological grade and less frequent expression of ER/PR In the North region of Brazil, $34.7 \%$ of samples were $3+$, with lower frequencies in the other four regions of the country.

Conclusion: Our findings provide estimates for the frequency of HER-2 positivity in Brazil and raise the hypothesis that biological differences may underlie the different distribution of breast-cancer phenotypes among different Brazilian regions.

Keywords: breast neoplasms, immunohistochemistry, in situ hybridization, erbB2, trastuzumab, HER-2.

\section{INTRODUCTION}

Breast cancer, which affects one out of eight US women during their lifetime, ${ }^{1}$ is the second most common tumor worldwide, with an estimated 1.67 million new cases and 522 thousand deaths in 2012. ${ }^{2}$ In Brazil, breast cancer is the most common tumor among women, affecting almost 60,000 patients in 2014. ${ }^{3}$ Currently, breast cancer is considered a group of different diseases on the basis of molecular subtypes, with this classification bearing relevant prognostic and predictive implications. ${ }^{4}$ Between 15 and
$20 \%$ of breast tumors display HER-2 gene amplification or overexpression of the HER-2 protein, ${ }^{5-7}$ a transmembrane tyrosine kinase receptor involved in cell proliferation and migration that confers worse prognosis, with faster disease progression and decreased survival, compared with HER-2-negative tumors. ${ }^{8}$ One of the most important advances in breast cancer therapy has been the introduction of trastuzumab and other HER-2-targeting antibodies, which increase the survival of patients with metastatic disease, ${ }^{9-11}$ and reduce the risk of relapse in early 
stages of the disease. ${ }^{12-14}$ As a result of these potential benefits, HER-2 testing is currently recommended for primary, recurrent and metastatic breast cancer lesions. ${ }^{7}$

In order to establish tumor HER-2 status in the clinic, a prerequisite for anti-HER-2 therapy, a paraffin-embedded tissue block of invasive breast carcinoma is required. When the primary tumor is assessed, specimens may be obtained through a core-needle biopsy, as well as from an incisional or excisional surgical procedure. ${ }^{7}$ More often, one of two methods is routinely used for the assessment of HER-2 status: immunohistochemistry (IHC) and one of the variants of in situ hybridization (ISH), namely fluorescent ISH (FISH), chromogenic ISH, and silver ISH. IHC is more widely available; however, it is more prone to interpretation error. Conversely, ISH methods have the disadvantages of requiring better tissue quality, being more expensive and technically demanding than IHC and of being limited to only a few centers. ${ }^{15}$ Because each assay type has diagnostic pitfalls, an algorithm has been proposed by the American Society of Clinical Oncology (ASCO) and the College of American Pathologists (CAP). ${ }^{7}$ As a result, samples classified as negative or positive by validated IHC analysis of their invasive tumor component require no further testing, whereas equivocal tests (i.e., samples classified as $2+$ by IHC) should be followed by ISH testing. ${ }^{7}$

There is a wealth of information in the literature regarding the frequency and determinants of HER-2 positivity in many countries and settings. On the other hand, only a few studies have been conducted in Brazil, most of which relatively small in size or retrospective in nature. ${ }^{16-18}$ In the current study, we prospectively attempted to investigate the frequency of HER-2-positive breast cancer in a large sample of Brazilian women, along with the standardization of preanalytic procedures used in the assessment of HER-2 and the association between HER-2 status and various tumor and patient features, including geographic location.

\section{Method}

\section{Role of the sponsor and ethical aspects}

This study was sponsored by Roche Brazil, which participated in the design, analysis and publication of results. The sponsor appointed a Scientific Committee, composed by pathologists and a medical oncologist, which was responsible for study oversight and which vouches for the accuracy of the data and the current manuscript. All participating patients provided written informed consent, and the study was approved by the Ethics Committees of all participating institutions. The initial version of the manuscript and subsequent changes based on input from all authors was under the responsibility of a medical-writing company (Dendrix, São Paulo).

\section{Study oversight}

In order to standardize the technique, the sponsor provided initial training with regard to study procedures, including the performance of IHC and ISH for HER-2, to all participating institutions. Positive and negative controls were provided by the Scientific Committee to participating laboratories. During the conduction of the study, the Scientific Committee regularly assessed the quality of the local readings, providing further training, if necessary.

\section{Selection of patients and samples}

In this prospective, observational study, an attempt was made to sequentially collect all samples of primary invasive breast cancer identified at participating pathology laboratories in the five geographic regions of Brazil during a defined period of time (from February, 2011, to December, 2012). Eligible patients were women with no neoadjuvant therapy regimen, and surgical specimens had to be obtained by radical mastectomy or segmentectomy, or histological material obtained by core-needle biopsy, or conventional surgical biopsy. Samples for which there was insufficient residual material for IHC and ISH were excluded from analysis. For each sample, locally collected data were centrally registered regarding preanalytic procedures, tumor size and location, margin status, histological type, architectural, nuclear and histological grade,${ }^{19}$ mitotic activity, presence of necrosis, lymphatic invasion and lymphoplasmacytic response, the number and nature (sentinel or not) of dissected and involved lymph nodes, and the presence and features of ductal carcinoma in situ (DCIS). IHC for estrogen receptor (ER), progesterone receptor (PR) and Ki-67 was performed at each participating laboratory using local standards, with expression of ER/PR in more than $1 \%$ of cells being considered positive. Data were centrally collected regarding antibody used, dilution, incubation time and temperature, antigen retrieval, amplification system, and result (negative or positive, according to the percentage of reactivity in the invasive neoplasm).

\section{IHC analysis for HER-2}

For HER-2, the IHC procedure was performed locally at each participating laboratory in an automated fashion, using Ventana equipment (Ventana Medical Systems, Tucson, AZ). Fixation was performed using $10 \%$ neutral buffered formalin at 15 to 20 times the volume of tissue 
and with the goal of penetrating no more than 2 to $3 \mathrm{~mm}$ of solid tissue or $5 \mathrm{~mm}$ of porous tissue in a 24-hour period. Tissue fixation was performed in sections $\leq 3 \mathrm{~mm}$ for 4 to 8 hours at room temperature $\left(15-25^{\circ} \mathrm{C}\right)$. Sections of $5 \mu \mathrm{m}$ were placed on electrically charged glass slides, samples were incubated with primary rabbit anti-HER-2 antibody PATHWAY ${ }^{\circledR}$ (4B5), and the UltraView DAB detection kit was used. All subsequent automated steps were undertaken using the BENCHMARK platform. A pathologist with IHC experience evaluated the controls and qualified the stained product before interpreting the results. Semi-quantitative grading of the reaction was used to classify each sample into one of four scores: ${ }^{20} 0$, cell membrane staining was absent or observed in less than $10 \%$ of the tumor cells; $1+$, weak or incomplete staining of the membrane in more than $10 \%$ of the tumor cells; $2+$, moderate to complete staining of the membrane in more than $10 \%$ of the tumor cells; $3+$, complete intense staining of the membrane observed in more than $30 \%$ of the tumor cells. Samples classified as 0 and $1+$ were defined as HER2-negative; $2+$, as equivocal; and $3+$, as HER2-positive. Samples classified as $2+$ were further evaluated by ISH for confirmation of the gene amplification. Figure 1 A depicts a representative case classified as score $3+$.

\section{ISH analysis for HER-2}

A pathologist previously trained by Roche Research Department in microscopic interpretation of breast carcinoma samples, ISH procedures and recognition of single and amplified copies of HER-2 (analyzed in a common optical microscope, using objective lenses of the order of 40X to 60X) assessed the controls before interpreting the outcomes. HER-2 gene was visible as a black signal (silver) and the chromosome 17 centromere (Chr17) was visible as a red signal (alkaline phosphatase). Figure 1B depicts a representative case. Signals were enumerated using 20X, 40X, 60X or 100X. Background silver and red markings were taken into account during enumeration. Only cells with representative diameters of the mean population of invasive carcinoma cells in the target area were evaluated. In genetically heterogeneous target areas for the number of HER-2 copies, only representative cells of the population of invasive carcinoma with the largest mean number of signals were counted. Heterogeneity, polysomy and monoallelic deletion were noted, if present. Once the adequate target area was identified, the number of copies of HER-2 and Chr17 present in 20 representative cells were evaluated. The status of the HER-2 gene was given by the ratio of the mean number of HER-2 copies to the mean number of copies of Chr17, per cell, in the invasive tumor component. HER-2 gene status was classified as negative, when the HER-2/Chr17 ratio was below 2.0, and positive, when the HER-2/Chr17 ratio was above 2.2. Cases with HER-2/Chr17 ratio between 1.8 and 2.2 were more closely investigated by the enumeration of 20 additional cells, with the final ratio being calculated taking into account the 40 cells counted.

\section{Statistical analysis}

Given the descriptive nature of this study, no formal sample-size calculation was performed. Patient and tumor characteristics were summarized in aggregate and according to groups of interest. With the aim of investigating features associated with HER-2 status, comparisons among groups were made using the Chi-square test for categorical variables and analysis of variance for continuous variables, with data transformation or use of the nonparametric Mann-Whitney (two groups) or Kruskal-Wallis (three or more groups) tests for non-normally distributed variables. All statistical analyses were performed using SAS $^{\circledR}$ software, version 9.3 (SAS Institute, Cary, NC), and two-tailed $\mathrm{p}$-values $<0.05$ were considered significant.

\section{RESULTS}

Overall characteristics of the laboratories and patients

Twenty-four Brazilian laboratories from 22 of 27 Brazilian Sates/Federal District participated in the study. From February 2011 to December 2012, 1,495 specimens of breast tissue were registered in the study database, 185 of which were excluded from analysis: 124 were not assessed due to major protocol violations (often because samples were obtained before center activation $[\mathrm{N}=84]$ or signed informed consent was missing $[\mathrm{N}=21])$. Therefore, a total of 1,310 samples were included in the analysis. The number of analyzed specimens per laboratory ranged from 3 to 188, with 22 of them contributing at least ten specimens and four contributing more than 100 specimens each. At sample collection, mean patient age was 55.4 years (range 22 to 93), and the state of origin was São Paulo (the most populous state in Brazil) and Rio Grande do Sul in 37.3 and $22.4 \%$ of cases, respectively. Among the patients with known menopausal status, $67.2 \%$ were postmenopausal.

\section{Preanalytic procedures}

Specimens were obtained from segmental mastectomy in $46.9 \%$ of cases, $34.4 \%$ came from radical mastectomy, $14.5 \%$ from large-core-needle biopsy, and $4.2 \%$ from conventional biopsy. The median time from surgery initiation to specimen collection was 1.2 hour; the median time 

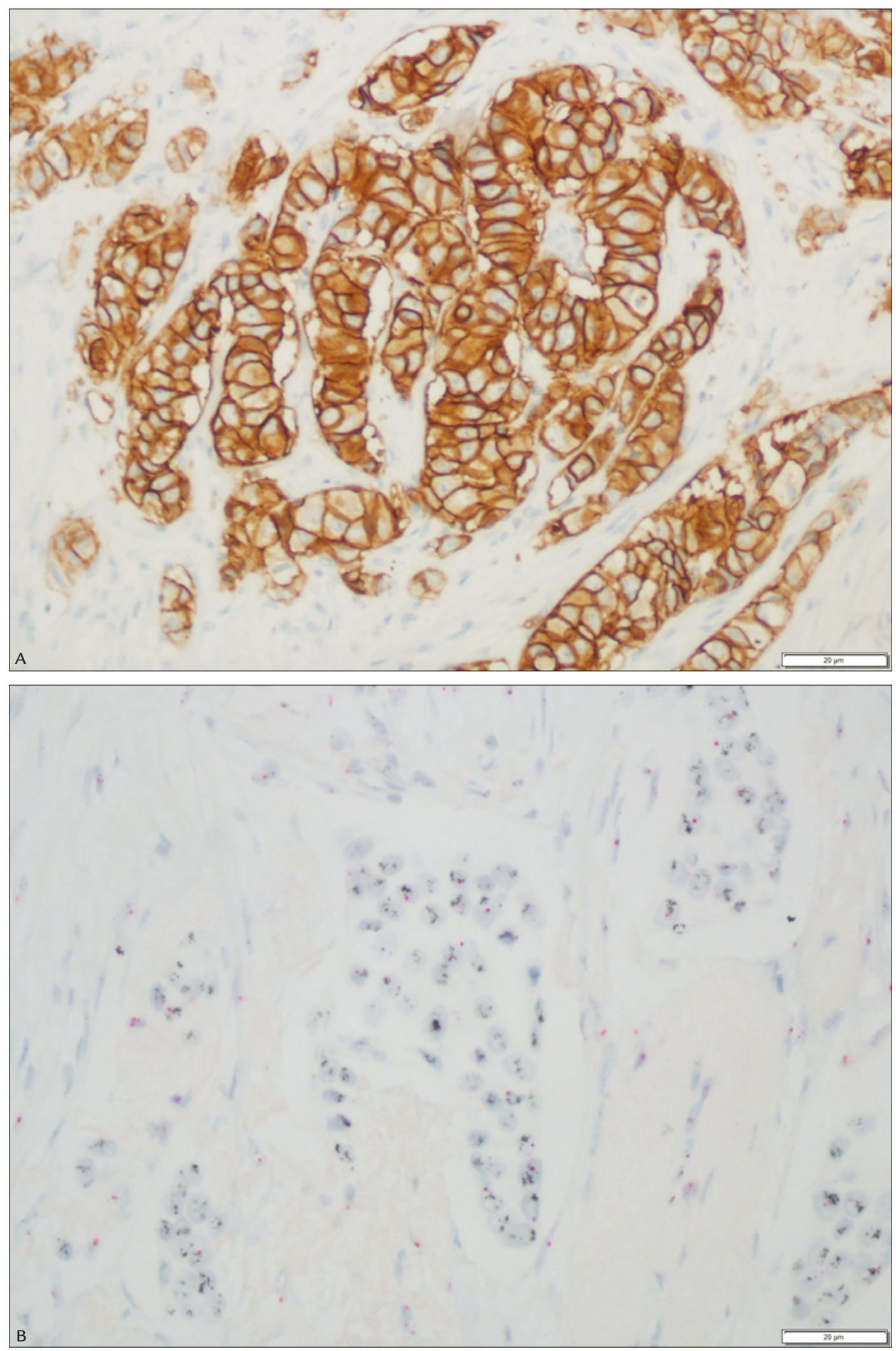

FIGURE 1 A. Representative microphotograph of a breast cancer specimen classified with a score of 3+ by immunohistochemistry (400x). B. Representative microphotograph of a breast cancer specimen classified as positive by in situ hybridization (400x). 
from surgery to sample registration in the laboratory was 6.3 hours; the median time from sample registration in the laboratory to gross examination was 19.0 hours; and the median time from specimen collection to gross examination was 24.0 hours (for $29.3 \%$ of the specimens, this time exceeded 48 hours). Specimens were processed fresh in $12.4 \%$ of the cases, and buffered formalin was the most commonly used fixative solution (62.1\%), followed by non-buffered saline formalin (36.0\%).

\section{Characteristics of tumor specimens}

Considering the 1,310 patients, $58 \%$ had undergone a prior core biopsy, $7.7 \%$ had a prior surgical biopsy, and $5.6 \%$ had the primary tumor already resected. Considering the 1,310 tumor samples included in the analysis, $85 \%$ were invasive breast carcinoma of no special type (IBC), and $5.4 \%$ were invasive lobular carcinoma (ILC). Other histological types, including mixed IBC and ILC (1.8\%), were less frequent. Tumors had a mean size of the long axis of $26.8 \mathrm{~mm}$ (range 0.7 to $170 \mathrm{~mm}$ ), were in the left and right breast in 49.6 and $49.2 \%$ of the cases, respectively. In $24.8 \%$ of the samples, the quadrant was unknown, while $42.2 \%$ of the tumors were in the upper outer quadrant, and $18.8 \%$ were in the upper medial quadrant. Nipple involvement was reported in $8.7 \%$ of the 652 cases with the information available. The resection margin was involved in $11.2 \%$ of cases, and the mean distance to the nearest margin of the tumor was $8.7 \mathrm{~mm}$. The most frequent features were poor tubule formation (grade $3 ; 64.3 \%$ ), nuclear grade $2(47.0 \%)$ and low mitotic index (54.7\%). Necrosis in the infiltrative component was reported in $24.4 \%$ of the specimens, with a median estimated percentage of necrosis of $10.0 \%$. Lymphovascular invasion was present in $37.9 \%$ of the specimens, and lymphoplasmacytic response was mild in $53.3 \%$. The sentinel lymph node was assessed in $56.2 \%$ of patients, identified in $77.6 \%$ of those cases, and involved in $67.8 \%$ of the latter. The mean numbers of positive and resected lymph nodes were 2.6 and 7.3, respectively. DCIS coexisted with invasive carcinoma in $46.7 \%$ of specimens; among these, $44.9 \%$ had nuclear grade 3 , and $55.9 \%$ had comedonecrosis. ER was tested in $80.9 \%$ of specimens, and was positive in $77.4 \%$ of these; PR was tested in $80.8 \%$ of specimens, and was positive in $67.8 \%$. Ki-67 was assessed in $57.3 \%$ of the specimens, with a mean estimated percentage of reactivity in the invasive neoplasm of $29.2 \%$.

\section{HER-2 status}

A mean of $101.9 \pm 120$ days had elapsed between the date of surgery and the date of the IHC analysis, and $230 \pm 172.2$ days until the ISH assessment. HER-2 analysis by IHC was possible in $99.4 \%$ of the samples, and results are displayed in Table 1. Using the ASCO/CAP criteria of $2007,{ }^{20}$ $72.2 \%$ of the specimens were negative, and $18.5 \%$ were positive. Among the $9.3 \%$ of samples with an IHC score of $2+$, all of which undergoing assessment by ISH, HER-2 status was considered positive in $15.7 \%$ of the samples, negative in $73.6 \%$, and inconclusive in $10.7 \%$ (Table 1 ). Thus, considering both methods, a total of 260 out of 1,302 specimens was HER-2-positive (20.0\%; 95CI 17.9-22.3).

\begin{tabular}{lc}
\multicolumn{2}{l}{ TABLE 1 HER-2 status of 1,302 analyzed specimens. } \\
\begin{tabular}{cc} 
Method and result & Number (\%) \\
\hline Immunohistochemistry $(\mathrm{N}=1,302)$ & $627(48.2 \%)$ \\
\hline 0 & $313(24.0 \%)$ \\
\hline $1+$ & $121(9.3 \%)$ \\
\hline $2+$ & $241(18.5 \%)$ \\
\hline $3+$ & \\
\hline In situ hybridization $(\mathrm{N}=121)$ & $89(73.6 \%)$ \\
\hline Negative & $19(15.7 \%)$ \\
\hline Positive & $13(10.7 \%)$ \\
\hline Inconclusive & $1,042(80.0 \%)$ \\
\hline Either method $(\mathrm{N}=1,302)$ & $260(20.0 \%)$ \\
\hline Negative or inconclusive
\end{tabular} \\
\hline \multicolumn{2}{l}{ Positive }
\end{tabular}

\section{Features associated with HER-2 status}

The association between selected patient/tumor features and HER-2 status was investigated using IHC scores (Table 2). There was no association between HER-2 scores and menopausal status when all IHC scores were considered. Likewise, there was no statistically significant association with histological type when a global test was used for the cross-tabulation of all IHC scores and histological types. However, HER-2 scores varied nominally according to individual histological types; for example, an IHC score of $3+$ was found in only six of 69 (8.7\%) invasive lobular carcinomas. Samples with a score of $3+$ came from significantly younger patients, had a higher histological grade, and less frequent association with ER or PR expression (Table 2).

When HER-2 scores were compared across the five geographic regions of Brazil, samples from the North region of the country were more likely to present a score of $3+$ than samples from other regions (Table 2). The distribution across the country regions was also investigated considering the following phenotypes defined based on the expression status of HER-2 and hormone receptors: phenotype I, tumors positive for ER or PR, but negative 
TABLE 2 Association between patient/tumor features and HER-2 status by immunohistochemistry.

\begin{tabular}{|c|c|c|c|c|c|}
\hline \multirow[t]{2}{*}{ Features } & \multicolumn{4}{|c|}{ HER-2 status } & \multirow[t]{2}{*}{ p-value } \\
\hline & 0 & $1+$ & $2+$ & $3+$ & \\
\hline \multicolumn{6}{|l|}{ Age, years } \\
\hline Mean $( \pm S D)$ & $56.3 \pm 12.2$ & $55.5 \pm 12.7$ & $57.7 \pm 12.8$ & $51.8 \pm 11.9$ & $<0.001$ \\
\hline \multicolumn{6}{|l|}{ Menopausal status } \\
\hline Postmenopausal & $69.7 \%$ & $66.3 \%$ & $72.9 \%$ & $57.7 \%$ & \multirow[t]{3}{*}{0.065} \\
\hline Premenopausal & $30.1 \%$ & $33.2 \%$ & $27.1 \%$ & $41.1 \%$ & \\
\hline Menarche & $0.2 \%$ & $0.5 \%$ & 0 & $1.1 \%$ & \\
\hline \multicolumn{6}{|l|}{ Histological grade* } \\
\hline Mean $( \pm S D)$ & $6.4 \pm 1.5$ & $6.4 \pm 1.5$ & $6.8 \pm 1.4$ & $7.1 \pm 1.4$ & $<0.001$ \\
\hline \multicolumn{6}{|l|}{ Estrogen receptor } \\
\hline Positive & $77.2 \%$ & $87.4 \%$ & $87.5 \%$ & $58.2 \%$ & \multirow[t]{2}{*}{$<0.001$} \\
\hline Negative & $22.8 \%$ & $12.6 \%$ & $12.5 \%$ & $41.8 \%$ & \\
\hline \multicolumn{6}{|l|}{ Progesterone receptor } \\
\hline Positive & $68.4 \%$ & $78.1 \%$ & $76.9 \%$ & $47.0 \%$ & \multirow[t]{2}{*}{$<0.001$} \\
\hline Negative & $31.6 \%$ & $21.9 \%$ & $23.1 \%$ & $53.0 \%$ & \\
\hline \multicolumn{6}{|l|}{ Geographic region } \\
\hline Midwest & $54.2 \%$ & $16.7 \%$ & $4.2 \%$ & $25.0 \%$ & \multirow[t]{5}{*}{$<0.001$} \\
\hline North & $40.8 \%$ & $20.4 \%$ & $4.1 \%$ & $34.7 \%$ & \\
\hline Northeast & $55.2 \%$ & $19.0 \%$ & $4.9 \%$ & $20.9 \%$ & \\
\hline Southeast & $47.1 \%$ & $23.5 \%$ & $12.0 \%$ & $17.4 \%$ & \\
\hline South & $44.8 \%$ & $30.1 \%$ & $9.6 \%$ & $15.5 \%$ & \\
\hline
\end{tabular}

SD: standard deviation.

*Histological grade was assessed using the system of Elston and Ellis. ${ }^{19}$ For each patient, the grade is the sum of individual grades for architecture, nuclear grade and mitotic activity (each individual grade ranging from 1 to 3 , and the total grade ranging from 3 to 9 ).

for HER-2 ( 0 or $1+$ by IHC, or $2+$ by IHC, but negative by ISH); II, tumors positive for HER-2 (3+ by IHC or positive by ISH), irrespective of the status of the hormone receptors; and III, triple-negative tumors (negative for HER-2, ER and PR). Since not all patients from all regions underwent ER/PR assessment, and given the exploratory nature of this analysis, no statistical tests were conducted; Figure 2 displays the distribution of the three phenotypes across geographic regions.

\section{Discussion}

The primary objective of the present study was to characterize the distribution of HER-2 status across Brazil, a large country with substantial ethnic and social heterogeneity. The estimated percentage of HER-2-positive breast tumors $(20.0 \%)$ is in line with estimates from other countries. ${ }^{20,21}$ With regard to previous studies from Brazil, Carvalho et al. have found a frequency of $19.4 \%$ of HER-2-positive tumors in a retrospective study using only IHC and involving 5,687 consecutive cases of invasive breast cancer assessed from July 2009 to March $2011 .{ }^{16}$ Of note, these authors used the same ASCO/CAP definition used here- in. We believe the patient sample investigated in the present study to be fairly representative of the general population of patients with breast cancer seen at public institutions from the Southeast and South regions of Brazil, which contributed nearly two-thirds of specimens, and which comprise $56.5 \%$ of the Brazilian population. ${ }^{22}$ With a mean age of approximately 55 years, IBC in the vast majority of cases, and ER/PR expression in nearly two-thirds of cases, such patients may be considered a convenience sample from this country.

Breast cancer is a major health problem worldwide. Determination of the expression status of HER-2 and hormone receptors is currently required for all breast tumors in order to establish the best therapeutic approach in individual patients. The ASCO/CAP guidelines recommend that a Food and Drug Administration-approved IHC, bright-field ISH or FISH assay should be preferentially used for HER-2 testing. ${ }^{7,20}$ Silver ISH is a rapid automated assay that has been shown to have a high concordance with FISH in determining the status of HER-2 gene amplification in invasive breast carcinoma. In a study conducted by Papouchado et al., in which 298 samples 


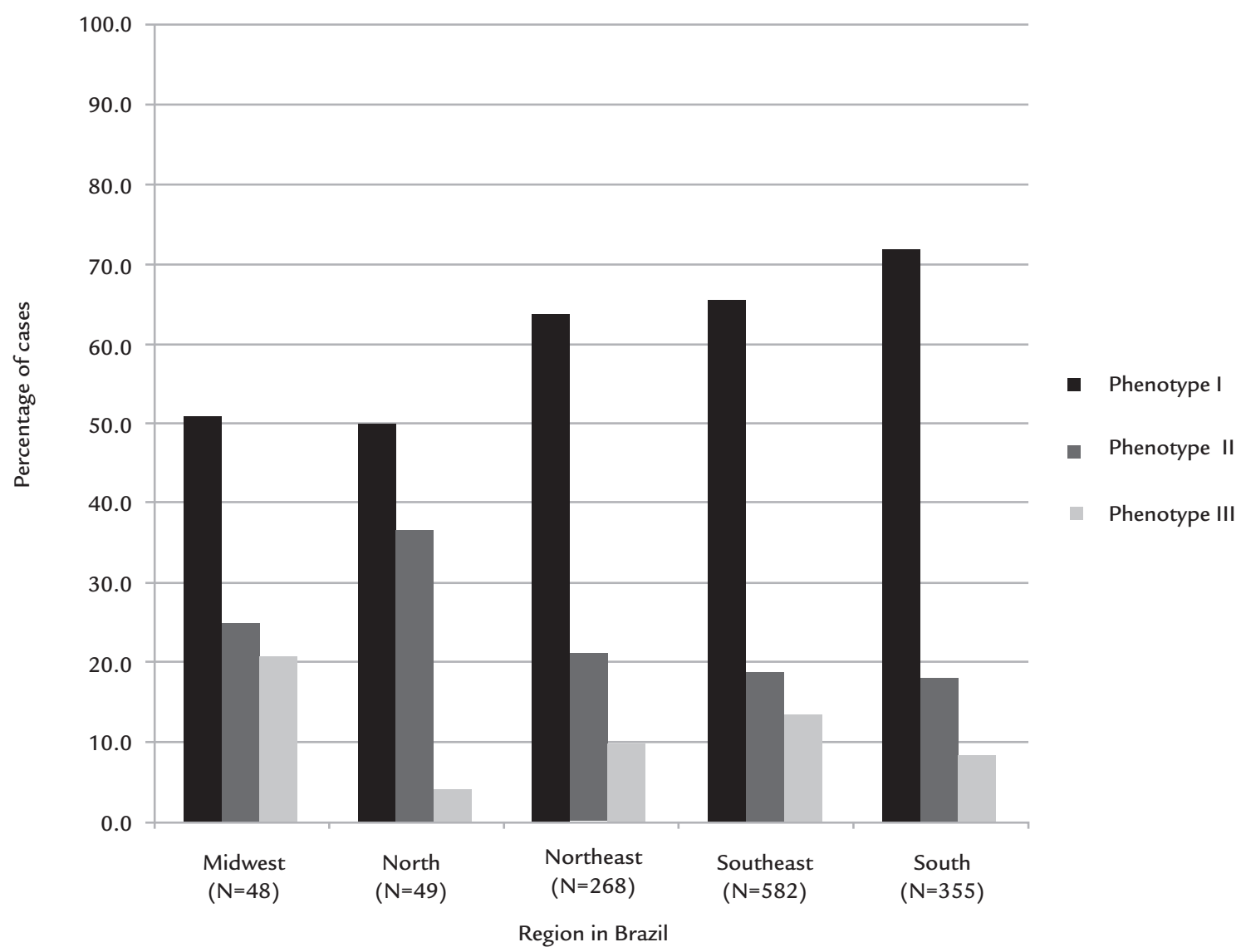

FIGURE 2 Distribution of tumor phenotypes per geographic region of Brazil, with number of samples analyzed in each region. Phenotype I denotes tumors positive for estrogen receptor (ER) or progesterone receptor (PR), but negative for HER-2 ( 0 or $1+$ by immunohistochemistry $[\mathrm{IHC}]$, or 2+ by IHC, but negative by in situ hybridization [ISH]); II, tumors positive for HER-2 (3+ by IHC or positive by ISH), irrespective of the status of ER/PR; and III, triple-negative tumors (negative for HER-2, ER and PR). The sum of percentages in each region does not equal $100 \%$ due to missing data on ER/PR assessment.

were evaluated by ten pathologists, an overall agreement of $98.9 \%$ between silver ISH and FISH was observed. ${ }^{23}$ Studies have shown a higher accuracy of HER-2 testing when it is performed at high-volume central reference laboratories rather than at local laboratories, with the discordance rate between local and central testing being as high as $26 \% .^{24,25} \mathrm{~A}$ low concordance between local and reference laboratories has also been reported in Brazil, and the authors have argued that it may be related to inexperience with HER-2 scoring, a low-volume load of HER-2 assays, and technical issues related to IHC in local laboratories. ${ }^{26}$ Given the impact of preanalytic variables IHC and FISH results, ${ }^{27}$ and aiming at improving the accuracy of HER-2 testing, the ASCO/CAP guidelines include recommendations regarding type of fixative, time between sample collection and placement into fixative, and fixation duration. According to the 2007 guideline, time from tissue acquisition to fixation should be as short as possible, with samples for HER-2 testing being fixed in $10 \%$ neutral buffered formalin for a minimum of 6 and a maximum of 48 hours. ${ }^{20}$ In the updated guideline, the maximum duration of fixation was altered to 72 hours. $^{7}$ In the present study, the median time from specimen removal to macroscopic examination was 24 hours, and for nearly one-third of specimens this interval exceeded 48 hours. For 162 specimens, processing was performed in fresh tissue.

Exploratory analyses were performed to investigate possible associations between HER-2 scores by IHC and tumor and patient characteristics. Of note, a lower frequency of positivity for the expression of $\mathrm{ER}$ and $\mathrm{PR}$ was observed for specimens with scores 0 and $3+$. This finding 
is probably explained by the fact that tumors scored as 0 are enriched for the triple-negative phenotype, whereas those scored as $3^{+}$are known to have less frequent expression of ER and PR than breast tumors in general. ${ }^{6}$ When the distribution of HER-2 status and breast-cancer phenotypes was analyzed considering the five regions of Brazil, the North region had a higher percentage of HER-2-positive tumors, whereas the Midwest region had a higher percentage of triple-negative tumors than the other regions (Figure 2). Interestingly, Carvalho et al. have reported higher percentages for the North region both for HER-2-positive and for triple-negative tumors. ${ }^{16}$ Likewise, a group from the Northeast region of Brazil reported that nearly $50 \%$ of 633 patients with invasive breast cancer had HER-2-positive tumors by IHC. ${ }^{17}$ The relevance of these findings is still unclear, and whether they represent underlying biological phenomena or simply the play of chance remains to be investigated. The lower number of samples from the North and Midwest regions as compared with the other three regions is one limitation of the current study.

\section{Conclusion}

In summary, one out of five invasive breast tumors diagnosed in Brazil is positive for HER-2. Identifying these cases has obvious therapeutic implications, and adequate use of testing algorithms should be widely implemented in order to ensure patients have the chance to derive the expected benefit. To our knowledge, this is the largest prospective study evaluating HER-2 status in Brazilian patients with invasive breast carcinoma. In addition to data regarding patient and tumor molecular characteristics, the current study provides important data on the procedures and materials used for the assessment of the expression status of HER-2 and hormone receptors in this country.

\section{Resumo}

Avaliação de HER-2 no câncer de mama invasivo no Brasil

Objetivo: Estimar a frequência de câncer de mama positivo para HER-2 no Brasil.

Método: Neste estudo observacional e prospectivo, verificamos o escore de HER-2 de espécimes de câncer de mama invasivo por imuno-histoquímica automatizada (IHQ). Para amostras classificadas como $2+$ por IHQ, fizemos hibridização in situ (HIS).

Resultados: De fevereiro de 2011 a dezembro de 2012, 1.495 espécimes de mama foram registrados, e 1.310 amostras coletadas por 24 centros foram analisadas. A idade mediana das pacientes foi 54 anos, e a maioria das amostras foram obtidas a partir de mastectomia segmentar (46,9\%) ou radical (34,4\%). O tipo histológico predominante foi o carcinoma invasivo da mama, sem tipo especial (85\%); 64,3\% tinham formação de túbulos (grau 3); e os receptores de estrógeno (RE)/progesterona (RP) foram positivos em $77,4 \% / 67,8 \%$ das amostras analisadas. Por IHQ, encontramos HER-2 negativo (0 ou $1+$ ) em $72,2 \%$ das amostras, e $3+$ em $18,5 \%$; os $9,3 \%$ de casos classificados como $2+$ foram analisados por HIS, e 15,7\% deles foram positivos (assim, 20,0\% das amostras foram positivas para HER-2 por qualquer método). Não encontramos associação entre escores de HER-2 e estado menopausal ou tipo histológico. Tumores classificados como 3+ vieram de pacientes mais jovens, tinham maior grau histológico e foi menos frequente a expressão de RE/RP. Na região Norte do Brasil, 34,7\% das amostras foram $3+$, com frequências mais baixas nas outras quatro regiões do país.

Conclusão: Nossos resultados permitem estimar a frequência de positividade do HER-2 no Brasil, gerando a hipótese de que pode haver diferenças biológicas subjacentes à distribuição dos fenótipos de câncer de mama entre as diferentes regiões brasileiras.

Palavras-chave: neoplasias da mama, imuno-histoquímica, hibridização in situ, erbB2, trastuzumabe, HER-2.

\section{References}

1. DeSantis C, Ma J, Bryan L, Jemal A. Breast cancer statistics, 2013. CA Cancer J Clin 2014; 64(1):52-62.

2. World Health Organization. International Agency for Research on Cancer. GLOBOCAN 2012: Estimated Cancer Incidence, Mortality and Prevalence Worldwide in 2012 [cited 2015 Nov 11]. Available from: http://globocan.iarc.fr.

3. Brasil. Ministério da Saúde. Instituto Nacional de Câncer. Estimativa 2014: Incidência de câncer no Brasil [cited 2015 Nov 8]. Available from: http:// www.inca.gov.br/wcm/dncc/2013/apresentacao-estimativa-2014.pdf

4. Sotiriou C, Pusztai L. Gene-expression signatures in breast cancer. N Engl J Med. 2009; 360(8):790-800.

5. Giordano SH, Temin S, Kirshner JJ, Chandarlapaty S, Crews JR, Davidson NE, et al. Systemic therapy for patients with advanced human epidermal growth factor receptor 2-positive breast cancer: American Society of Clinical Oncology clinical practice guideline. J Clin Oncol. 2014; 32(19):2078-99.

6. Yaziji H, Goldstein LC, Barry TS, Werling R, Hwang H, Ellis GK, et al. HER2 testing in breast cancer using parallel tissue-based methods. JAMA. 2004; 291(16):1972-7.

7. Wolff AC, Hammond ME, Hicks DG, Dowsett M, McShane LM, Allison KH, et al.; American Society of Clinical Oncology; College of American Pathologists. Recommendations for human epidermal growth factor receptor 2 testing in breast cancer: American Society of Clinical Oncology/College of American Pathologists clinical practice guideline update. J Clin Oncol. 2013; 31(31):3997-4013.

8. Slamon DJ, Clark GM, Wong SG, Levin WJ, Ullrich A, McGuire WL. Human breast cancer: correlation of relapse and survival with amplification of the HER-2/neu oncogene. Science. 1987; 235(4785):177-82.

9. Slamon DJ, Leyland-Jones B, Shak S, Fuchs H, Paton V, Bajamonde A, et al. Use of chemotherapy plus a monoclonal antibody against HER2 for metastatic breast cancer that overexpresses HER2. N Engl J Med. 2001; 344(11):783-92. 
10. Verma S, Miles D, Gianni L, Krop IE, Welslau M, Baselga J, et al. Trastuzumab emtansine for HER2-positive advanced breast cancer. N Engl J Med. 2012; 367(19):1783-91.

11. Swain SM, Baselga J, Kim SB, Ro J, Semiglazov V, Campone M, et al.; CLEOPATRA Study Group. Pertuzumab, trastuzumab, and docetaxel in HER2-positive metastatic breast cancer. N Engl J Med. 2015; 372(8):724-34.

12. Joensuu H, Kellokumpu-Lehtinen PL, Bono P, Alanko T, Kataja V, Asola R, et al.; FinHer Study Investigators. Adjuvant docetaxel or vinorelbine with or without trastuzumab for breast cancer. N Engl J Med. 2006; 354(8):809-20.

13. Romond EH, Perez EA, Bryant J, Suman VJ, Geyer CE, Jr, Davidson NE, et al. Trastuzumab plus adjuvant chemotherapy for operable HER2-positive breast cancer. N Engl J Med. 2005; 353(16):1673-84.

14. Smith I, Procter M, Gelber RD, Guillaume S, Feyereislova A, Dowsett M, et al.; HERA study team. 2-year follow-up of trastuzumab after adjuvant chemotherapy in HER2-positive breast cancer: a randomised controlled trial. Lancet. 2007; 369(9555):29-36.

15. Hicks DG, Tubbs RR. Assessment of the HER2 status in breast cancer by fluorescence in situ hybridization: a technical review with interpretive guidelines. Hum Pathol. 2005; 36(3):250-61.

16. Carvalho FM, Bacchi LM, Pincerato KM, Van de Rijn M, Bacchi CE. Geographic differences in the distribution of molecular subtypes of breast cancer in Brazil. BMC Womens Health. 2014; 14:102.

17. de Macedo Andrade AC, Ferreira Junior CA, Dantas Guimaraes B, Pessoa Barros AW, Sarmento de Almeida G, Weller M. Molecular breast cancer subtypes and therapies in a public hospital of northeastern Brazil. BMC Womens Health. 2014; 14:110.

18. Schiavon BN, Jasani B, de Brot L, Vassallo J, Damascena A, Cirullo-Neto J, et al. Evaluation of reliability of FISH versus brightfield dual-probe in situ hybridization (BDISH) for frontline assessment of HER2 status in breast cancer samples in a community setting: influence of poor tissue preservation. Am J Surg Pathol. 2012; 36(10):1489-96.
19. Elston CW, Ellis IO. Pathological prognostic factors in breast cancer. I. The value of histological grade in breast cancer: experience from a large study with long-term follow-up. Histopathology. 1991; 19(5):403-10.

20. Wolff AC, Hammond ME, Schwartz JN, Hagerty KL, Allred DC, Cote RJ, et al.; American Society of Clinical Oncology/College of American Pathologists. American Society of Clinical Oncology/College of American Pathologists guideline recommendations for human epidermal growth factor receptor 2 testing in breast cancer. Arch Pathol Lab Med. 2007;131(1):18-43.

21. Witton CJ, Reeves JR, Going JJ, Cooke TG, Bartlett JM. Expression of the HER1-4 family of receptor tyrosine kinases in breast cancer. J Pathol. 2003; 200(3):290-7.

22. Brasil. Instituto Brasileiro de Geografia e Estatística. Censo 2010 [cited 2015 Nov 18]. Available from: http://censo2010.ibge.gov.br/.

23. Papouchado BG, Myles J, Lloyd RV, Stoler M, Oliveira AM, Downs-Kelly E, et al. Silver in situ hybridization (SISH) for determination of HER2 gene status in breast carcinoma: comparison with FISH and assessment of interobserver reproducibility. Am J Surg Pathol. 2010; 34(6):767-76.

24. Reddy JC, Reimann JD, Anderson SM, Klein PM. Concordance between central and local laboratory HER2 testing from a community-based clinical study. Clin Breast Cancer. 2006; 7(2):153-7.

25. Roche PC, Suman VJ, Jenkins RB, Davidson NE, Martino S, Kaufman PA, et al. Concordance between local and central laboratory HER2 testing in the breast intergroup trial N9831. J Natl Cancer Inst. 2002; 94(11):855-7.

26. Wludarski SC, Lopes LF, Berto ESTR, Carvalho FM, Weiss LM, Bacchi CE. HER2 testing in breast carcinoma: very low concordance rate between reference and local laboratories in Brazil. Appl Immunohistochem Mol Morphol. 2011; 19(2):112-8.

27. Moatamed NA, Nanjangud G, Pucci R, Lowe A, Shintaku IP, ShapourifarTehrani S, et al. Effect of ischemic time, fixation time, and fixative type on HER2/neu immunohistochemical and fluorescence in situ hybridization results in breast cancer. Am J Clin Pathol. 2011; 136(5):754-61. 